\title{
O contexto comunicativo como estratégia de mediação televisiva - considerações sobre o Jornal da MTV 1
}

\author{
Juliana Freire Gutmann² \\ Faculdades Jorge Amado / Faculdade Social da Bahia
}

\begin{abstract}
Resumo: Inspirado nas discussões de Simon Frith sobre as produções de sentido e o consequente jogo valorativo da cultura pop e tendo como ferramenta analítica certos pressupostos da sócio-semiótica, este artigo pretende observar os aspectos de um programa televisivo (Jornal da MTV) que dizem sobre as estratégias de construção de um contexto comunicativo específico que dialoga com referências éticas e estéticas da música popular massiva. Em um sentido mais amplo, o trabalho explora o contexto como um dos operadores de análise para a identificação dos modos de endereçamento de programas televisivos.
\end{abstract}

Palavras-chave: Jornal da MTV, estudos culturais e semiótica.

Résumé : Cet article s'inspire des discussions de Simon Frith sur les productions de sens et sur le jeu de mise en valeur de la culture pop qui en découle. Il utilise comme outil analytique certains présupposés de la sociosémiotique. L'article se propose d'observer les aspects d'un programme de télévision (le Journal de MTV) qui concernent les stratégies de construction d'un contexte communicatif spécifique qui dialogue avec les références éthiques et esthétiques de la musique populaire de masse. Dans un sens plus large, le travail explore le contexte comme un des opérateurs de l'analyse servant à identifier comment les programmes de télévision s'adressent au public.

Mots-clés : Journal de MTV, études culturelles et sémiotique

\footnotetext{
${ }^{1}$ A primeira versão deste artigo foi apresentada no XIV Encontro Anual da COMPÓS (2005) no GT Produção de Sentidos nas Mídias - Universidade Federal Fluminense (UFF), Niterói, RJ.

${ }^{2}$ Mestre em Comunicação e Cultura Contemporâneas pela UFBa. Pesquisadora Associada Mestre dos Grupos de Pesquisa Análise de Telejornais e Mídia e Música Popular Massiva do Programa de Pós Graduação em Comunicação e Cultura Contemporâneas da UFBa.

Professora do curso de jornalismo das Faculdades Jorge Amado e da Faculdade Social da Bahia.
} 


\begin{abstract}
Inspired by Simon Firth's discussions about meaningful productions and the consequent value of popular culture and using certain assumptions of the social-semiotics, this article proposes the observation of the features of a television program that regard the strategies of the formation of a particular communicative context that dialogues with ethical and aesthetical references of popular music. In a wider sense, this study explores the context as one of the operators of investigation to identify ways of addressing television programs.
\end{abstract}

Key words: MTV's Journal, cultural studies and semiotics

Resumen: Inspirado en las discusiones de Simon Frith sobre las producciones de sentido y el consequente partido valorativo de la cultura pop y teniendo como herramienta analítica ciertos presupuestos de la sociosemiótica, este artículo pretende observar los aspectos de uno programa televisivo que dicen sobre las estrategias de construcción de un contexto comunicativo específico que dialoga con referencias éticas y estéticas de la canción popular massiva. En un sentido más amplio, el trabajo explora el contexto como uno de los operadores de análisis para la identificación de los modos de direccionamiento de programas televisivos.

Palabras-llave: Jornal da MTV, estudios culturales y semiotica.

Music Television. Um modo de fazer televisão que se propõe musical sugere um ambiente de referências e experimentações baseadas na interação entre TV e música popular massiva. Desde sua concepção, a MTV incorporou a idéia de um canal televisivo construído com base em uma proposta estética inspirada no universo da cultura pop ${ }^{3}$, tendo o videoclipe como sinônimo de forma cultural. Hoje, mais que um veículo de promoção e divulgação dos produtos da indústria fonográfica, a rede se revela como um ambiente promissor da partilha de gostos, valores e marcas identitárias.

\footnotetext{
3 O termo "cultura pop" se refere à cultura popular massiva, a chamada cultura midiática. Vale ressaltar que os estudos brasileiros e franceses observam uma distinção entre cultura popular (de feições folclóricas) e cultura pop (popular midiática) que nem sempre é seguida pelos estudos culturais de língua inglesa. Neste trabalho, ao falar de cultura e música "pop" ou "popular" me refiro a este segundo aspecto.
} 
Entre os formatos que atuam neste fluxo midiático, encontra-se o Jornal da $M T V$, programa voltado para a veiculação dos acontecimentos ${ }^{4}$ do campo musical. O Jornal estreou em 2002 comandado por Fábio Massari e exibido semanalmente, mas ganhou nova versão em 2003, quando passa a ser veiculado de segunda a quinta à oh e investe na atuação de dois apresentadores, Edgard Picolli e Rafa, que desempenham papéis distintos e se encontram inseridos em diferentes cenários, também com funções significantes específicas. Uma terceira mudança ocorre em 2005, quando Sarah Oliveira assume, ao lado de Rafa, a apresentação do programa, que permanece no mesmo local na grade de programação, mas ganha uma edição dominical intitulada Jornal da MTV Semana Rock. No ano de 2006, o programa muda novamente de apresentadores e passa a ser comandado por Leo Madeira e Carla Lamarca.

Ao longo desses anos, o Jornal da Music Television passou por reformulações formais e discursivas que respondem por configurações específicas voltadas para a produção de um efeito jornalístico que tem a música como objeto de mediação. Em vista da impossibilidade de abordar neste artigo as quatro experimentações e re-experimentações significas de um "mesmo" programa, por hora, irei analisar apenas a segunda e mais longa versão do Jornal, exibida entre 2002 e 2003.

Dentro do contexto de uma televisão musical, o Jornal da MTV se apresenta como um meio de difusão da produção fonográfica nacional e internacional. Entre os assuntos tratados, destacam-se lançamentos de discos, clipes e publicações sobre música, artistas em estúdio, cobertura de shows e festivais, bandas novas, gravação de videoclipe, matérias atemporais, que normalmente contextualizam cenas, movimentos e estilos ou retomam fatos antigos, repercussão de assuntos polêmicos, curiosidades do show business e prestação de serviço (datas de shows, preços, locais).

$\mathrm{O}$ viés de abordagem do programa é fundado no apelo à proximidade com um tipo específico de telespectador/ ouvinte, investida traduzida nos dispositivos enunciativos e nas matérias significantes que compõem o Jornal (cenários, tipos de

\footnotetext{
4 A discussão sobre o valor notícia dos acontecimentos do universo da música mereceria uma análise aprofundada, o que não é o objetivo deste artigo. O interesse aqui se volta para o contexto discursivo no qual se dá o processo de mediação de tais eventos, sejam eles lançamentos de discos e clipes, shows etc.
} 
enquadramento e movimentos de câmera, vinhetas, edição etc.). A estratégia sugere uma audiência familiarizada com referências da cultura pop e juvenil identificadas com os formatos breves (como os videoclipes e as canções) concebidos no rastro do papel catalisador da música popular massiva. Características como narrativa sintética e não linear, multiplicidade de referências plásticas e edição fragmentada evidenciam um certo dialeto que demarca traços identitários reconhecíveis. Ao mesmo tempo, o programa investe numa espécie de re-elaboração do formato tradicional de um jornal televisivo, negociando com elementos deste gênero ora para borrar as suas marcas, ora para reiterá-las, atestando um lugar de fala autorizado.

Inspirada nas formulações de Simon Frith sobre os valores éticos e estéticos do universo da música pop, a operação analítica aqui proposta irá investir no modo como o Jornal da MTV se insere neste ambiente valorativo. A análise levará em conta a articulação entre certos valores e marcas identitárias da cultura pop e os dispositivos da linguagem televisiva no sentido de observar os aspectos do programa que dizem sobre as estratégias de construção de uma situação específica para a veiculação de notícias do campo musical, o que é identificado aqui como contexto comunicativo $^{5}$. Neste artigo, irei concentrar a minha observação na atuação dos dois apresentadores. Portanto, ainda que a consideração das estratégias discursivas adotadas nas reportagens, entrevistas e em dispositivos televisivos como vinhetas e chamadas de bloco forneçam valiosas pistas para se entender o modo como o olhar do telespectador é convocado, esta análise se concentra nas configurações enunciativas construídas para e pelos dois mediadores.

O debate aqui proposta tem os Estudos Culturais como lugar de fala e busca, em certos pressupostos semióticos, ferramentas para a viabilização da análise de um produto da cultura midiática. O percurso analítico apresentado se baseia no conceito

\footnotetext{
5 No âmbito da pesquisa que deu origem a este artigo, o contexto comunicativo é tomado como um dos operadores de análise para a identificação dos modos de endereçamento do Jornal da MTV. Tal identificação é fruto de discussões realizadas pelo Grupo de Pesquisa de Análise de Telejornais do Programa de Pós-graduação em Comunicação e Cultura Contemporâneas da UFBa para a interpretação dos modos de endereçamento de programas televisivos. Além do contexto, o grupo desenvolveu e vem adotando os seguintes operadores: temática, organização das editorias e proximidade com a audiência, pacto sobre o papel do jornalismo, mediador, relação com as fontes de informação, formatos de apresentação da notícia, recursos técnicos a serviço do jornalismo, recursos da linguagem televisiva e texto verbal.
} 
de textualidade ${ }^{6}$ e em pressupostos de estudos mais recentes da sócio-semiótica ${ }^{7}$ sobre os regimes de troca entre sujeitos a partir da interação entre o modo de enunciação e um certo lugar social ${ }^{8}$. Esta discussão se baseia em parte da minha pesquisa de mestrado9, já concluída, dedicada a compreender os modos de endereçamento deste programa televisivo que, ao se voltar para a mediação dos acontecimentos do campo da música popular massiva, investe em uma espécie de reexperimentação de marcas genéricas do telejornalismo.

\section{O contexto comunicativo - operador da análise televisiva}

O contexto comunicativo compreende os enunciadores (representados pelos mediadores dos programas televisivos), os enunciatários (a audiência presumida que também adquire diversas figurativizações no texto) e as circunstâncias espaciais e temporais nas quais o processo comunicativo de um programa televisivo se dá. Portanto, o operador se refere ao modo como os mediadores se apresentam e apresentam os seus interlocutores e diz sobre os lugares de fala que ocupam os sujeitos da enunciação nos programas. Nessa perspectiva, procura-se entender como os textos televisivos constroem posições; como eles descrevem e põem em relação os seus interlocutores. O contexto é a situação que regula o que vai ser dito a partir do

\footnotetext{
${ }^{6}$ O conceito de textualidade é discutido pelo semioticista italiano Paolo Fabri (1999). Diferentemente da idéia de texto trabalhada por Umberto Eco (1984), que pressupõe uma análise fechada no objeto em si, Fabri se coloca a favor de uma semiótica mais ampla, reivindicando a consideração dos estilos semióticos das culturas. $\mathrm{O}$ autor valoriza o caráter discursivo dos textos e integra a noção de enunciação ao seu aparato metodológico. O objeto de análise deste artigo evidencia a necessidade de tais considerações. Uma observação puramente imanente empobreceria o entendimento de importantes aspectos do Jornal da MTV, aqueles referentes ao ambiente midiático e identitário ao qual ele pertence. A consideração do jogo enunciativo evocado pelo programa também é fundamental para o entendimento de suas projeções discursivas.

7 Segundo Eliseo Veron (1998), o objetivo de uma sócio-semiótica é dar conta das condições de produção e reconhecimento de um discurso. Tal perspectiva parte dos discursos sociais e trata de compreender suas propriedades e seus modos de funcionamento em um determinado contexto.

${ }^{8}$ Este trabalho se baseia na observação contínua do programa durante dois períodos distintos localizados no primeiro e no segundo semestre de 2004. O primeiro período inclui as edições veiculadas entre os dias 05/04/04 e 15/04/04 e o segundo corresponde às edições exibidas de 15/11/04 a 25/11/04. Este corpus analítico é composto por 16 edições de 30 minutos de duração cada.

9 GUTMANN, Juliana Freire. Jornal da MTV em três versões. Gênero e modo de endereçamento como estratégias de mediação musical. Salvador, UFBA, 2005 (Dissertação de mestrado apresentada ao Programa de Pós-Graduação em Comunicação e Cultura Contemporâneas).
} 
reconhecimento, por parte do programa, do seu receptor, da sua competência cultural e daquilo que é partilhado com ele. Por isso, para entender o contexto é preciso entender como o sujeito que tem voz reconhece o "outro" e o posiciona no texto.

Nessa perspectiva, o contexto comunicativo estabelecido no e pelo Jornal da $M T V$ funciona como uma chave para o entendimento do tipo de relação proposta com o espectador que, por sua vez, relaciona-se a um outro contexto que extrapola o programa (o universo da música popular massiva). Aqui, a observação do contexto instaurada através do programa deflagra o modo como certos valores socialmente reconhecidos na esfera da música popular massiva são acionados no texto para a construção de uma situação comunicativa que possibilite a atualização do (tele) jornalismo.

\section{Valores, sentidos e uma situação}

Simon Frith (1998) defende que a compreensão do universo da música pop passa pelo entendimento do modo através do qual os juízos de valor sobre as suas manifestações são articulados, uma vez que essas experiências valorativas também dão conta de parte do significado das produções musicais. Para o autor, o próprio engajamento no universo da música depende de uma certa habilidade em apontar as nossas preferências e desacordos: "se as relações sociais são constituídas na prática cultural, nosso senso de identificação e diferença é estabelecido no processo de discriminação" (1998, p.18). Assim, ao afirmar que os produtos musicais estão disponíveis ao consumo porque carregam determinadas instruções de leitura sujeitas a valorações, Frith admite que esses juízos são articulados a partir de códigos partilhados. Transformadas em rituais de "gostos" e "desgostos", essas produções de sentido seriam também uma forma de delimitar as fronteiras identitárias do público, o que significa que o entendimento das experiências valorativas próprias da cultura pop só se tornaria possível através da consideração dos contextos em que elas são construídas e sustentadas. Os julgamentos culturais, portanto, no âmbito da cultura pop, não se apresentam simplesmente como expressões de subjetividade, mas como potenciais reveladores de identidades. 
Ora, se os juízos de valor são experiências localizadas, o debate sobre o poder estético dos produtos da cultura popular dependerá do entendimento do tipo de discurso utilizado para articular esses julgamentos em contextos sócio-culturais específicos. Ao afirmar que os sentidos e valores das produções musicais precisam ser entendidos a partir de um certo lugar de fala, que agregue estilos de vida, hábitos e preferências estéticas, Frith aponta para a importância das questões ideológicas e sociológicas, também constitutivas de tais manifestações. Para o autor, no jogo valorativo da música pop, não existe uma estética sem uma ética: “'Bom' e 'mau' são palavras-chave porque sugerem que os julgamentos estéticos e éticos são articulados juntos: não gostar de um disco não é apenas uma questão de gosto, é também uma questão de moralidade" (1989, p. 72).

Transportando tais considerações para o objeto de análise deste artigo, o Jornal da MTV, é possível afirmar que o entendimento das produções de sentido do programa passa necessariamente pela consideração da situação comunicativa construída no texto midiático pelos seus sujeitos de fala, os enunciadores e enunciatários. É justamente neste jogo estético-valorativo, baseado na partilha de códigos, gostos e saberes, que se fundamenta o contexto do Jornal. A sua relação com o espectador é fundada em um jogo de proximidade que requer uma troca de saberes e interesses e um certo acordo de atuação entre as partes de um jogo conhecido. Tais instruções são dadas no e pelo texto, como se este dissesse ao telespectador: "partilhamos de uma certa cultura e de uma certa visão de mundo".

O Jornal se deixa assistir a partir de um conjunto de marcas coerentes com o fluxo televisivo segmentado da MTV. Este engajamento requer um ouvinte com experiências prévias de leitura que dialogue com o texto levando em conta hábitos específicos de consumo musical e de audiência televisiva, o que inclui certas estratégias interpretativas, sensibilidade estética, graus de atenção, objetivos e desejos (ELLSWORTH, 2001). O programa não se dirige a qualquer ouvinte, mas àquele familiarizado com os apelos da cultura pop, dotado de um saber anterior sobre as cenas, estilos e movimentos musicais. A partir dessa premissa, o telespectador é solicitado para ter acesso a um mundo de hábitos compartilhados, o que marca o clima de intimidade evocado. O Jornal da MTV simula uma situação de bate-papo entre amigos de um mesmo universo identitário e desse modo convoca o público para 
"trocar uma idéia"1o sobre determinada banda, show, clipe. Esta situação se materializa em diversas formas significantes: os dispositivos técnicos, visuais e verbais que solicitam o engajamento da recepção. Tal convocação resulta de um ato comunicativo regido pela co-construção de sentido que leva em conta as condições de produção e reconhecimento do texto.

\section{Um jornal e dois lugares de fala}

As configurações enunciativas através das quais se operacionaliza o diálogo do programa com o público se valem da construção de diferentes lugares de fala e da consequente personalização dos seus apresentadores. Os mediadores Edgard e Rafa (propositadamente creditados, no programa, pelo primeiro nome) desempenham papéis distintos e se encontram inseridos em cenários com efeitos pretendidos específicos. Edgar comanda o Jornal à frente da bancada principal e representa mais claramente a figura do âncora. Já Rafa se mostra em uma espécie de cenário acessório, de onde faz as vezes da audiência.

Como estratégia retórica, os delegados do discurso do Jornal recorrem a dispositivos visuais e apelos verbais para imprimir um estilo próprio ao processo de mediação, ainda que este esteja sempre vinculado às marcas identitárias da MTV e, em um sentido mais amplo, à cultura popular massiva. O clima criado para os dois cenários, os movimentos corporais, o tom e o teor valorativo das falas, o uso excessivo dos pronomes pessoais são recursos utilizados para os dois VJs11. se colocarem explicitamente no discurso. Além de potencializar o clima de intimidade assumido, as personalizações funcionam para demarcar os distintos papéis exercidos pelos apresentadores.

Os dois cenários do programa sugerem diferentes ambientes significantes, reforçando lugares de fala fundamentais para as produções de sentido na música pop: de um lado a voz legitimada do jornalista, do outro a fala mais emotiva do fã. Da bancada principal Edgard Picolli personifica a voz oficial do jornalismo da MTV,

\footnotetext{
${ }^{10}$ No sentido de partilha, conversa. Para se referir às entrevistas com os artistas, os apresentadores do programa utilizam expressões como "fomos trocar uma idéia", "bater um papo" etc.

${ }^{11}$ Video-jockeys. Os apresentadores da MTV são denominados VJs em referência aos DJs (Disc-jockeys), que são os responsáveis pela execução de músicas em clubes, festas e emissoras de rádio.
} 
atuando como âncora. O cenário possui fundo azul com o logotipo do programa e um painel lateral com discretas inscrições dos protagonistas das notícias veiculadas: Los Hermanos, Nação Zumbi, R.E.M, Radiohead, Frejat, Retrofoguetes etc. Sobre a bancada branca figura uma pilha de publicações especializadas em música. As revistas e jornais colocados de modo estratégico são uma pista importante para localizar a posição do apresentador: o jornalista bem informado que sabe de onde e sobre o que fala. Edgard costuma abrir uma das revistas, mostrar para o público e traduzir trechos de reportagens. O cenário construído e os dispositivos televisivos acionados para a cena sugerem um clima de autoridade fundamental para o processo da mediação.

De acordo com Simon Frith, no jornalismo musical, “a questão não é apenas dizer se um grupo é bom ou ruim, mas saber quem tem autoridade para falar isso" (1989, p.9). Para o autor, este lugar do crítico pressupõe conhecimento histórico sobre música e uma certa familiaridade com a audiência, suas necessidades e valores. No Jornal da MTV, Edgard é colocado neste local autorizado, cabendo a ele a função de emitir opiniões sobre produtos e eventos musicais. $\mathrm{O}$ apresentador tem um quadro diário, o Som de Hoje, em que escolhe um CD e ouve junto com a audiência. Tudo ocorre como numa mini audição: Edgard pede para aumentar o som, escuta, mostra a capa e encarte, tece comentários e traz informações sobre a banda (origem, influências, tipo de música etc.). Vale lembrar que o VJ tem uma longa trajetória na emissora, onde atua desde 1992, e já esteve à frente de importantes programas como Nação e Contato MTV (antiga versão do telejornal da rede, exibida entre 2000 e 2001), fato que garante legitimidade para o seu papel.

Diferentemente deste primeiro lugar, que se assemelha a uma fachada de um telejornal para impor autoridade à enunciação, o segundo cenário simula uma espécie de ambiente privado. Com cores vivas (vermelho e amarelo), o espaço comporta uma mesa com um computador, revistas e papéis espalhados e prateleiras com objetos colocados de forma despojada (CDs, livros e um disco voador de brinquedo). A "parede" é repleta de posters, fotos, panfletos de shows e adesivos de artistas de rock. A cena é também ilustrada por uma guitarra encostada no canto do "quarto". O clima criado sugere um universo de fã para potencializar o papel desempenhado pelo segundo apresentador. Mais jovem e menos experiente, Rafa é 
identificado apenas pelo seu apelido, o que revela uma intenção de aproximação ainda maior com a audiência.

Do seu "quarto", o VJ se divide entre a função de apresentar o jornal, ainda que na posição de coadjuvante, e representar a figura do telespectador, o fã que coleciona discos e posters de seus ídolos e vibra com as novidades do mundo pop. A passagem em que ele introduz a matéria sobre B.B. King, no dia 14/04/04, ilustra tal intenção. Rafa aparece segurando uma guitarra para chamar a reportagem: "Pega um bloquinho e anota aí porque o Jornal da MTV tem os conselhos do mestre B.B. King para os amantes das seis cordas". Com o instrumento nos braços e um certo ar de empolgação, o apresentado parece representar o próprio telespectador a quem ele se dirige. É também reservada a ele a função de se comunicar diretamente com o público pela internet através dos quadros Manda aí (perguntas enviadas por e-mails pela audiência) e Histeria (enquete semanal do Jornal). Nos dois quadros, o VJ fala explicitamente com a audiência, ao fazer uso do pronome "você" ou citar o nome do internauta/ telespectador, e geralmente é enquadrado em primeiro plano, o que potencializa o efeito de intimidade com a audiência. Aqui, uma informação que estaria fora do texto é fundamental para o entendimento do seu papel: Rafa ingressou na MTV em 2002 através de um concurso realizado com jovens telespectadores da emissora, o Caça VJ.

É possível identificar os apresentadores do Jornal da MTV com o que Eliseo Veron (1983) chama de "apresentadores modernos" ou "meta enunciadores". Diferentemente dos "ventríloquos", que se afirmam como meros pontos de passagem de um discurso informativo através da redução dos gestos e expressões, enunciações desprovidas de modalizações, cenário limitado etc., os VJs da MTV exploram exaustivamente o contato com o público via mediatização corporal, o que enriquece o clima íntimo e descontraído da troca comunicativa. Edgard Picolli, posicionado sempre de pé, movimenta-se com naturalidade pelo cenário: escora-se lateralmente ou apóia os cotovelos na bancada, coça o queixo, passa a mão no cabelo e se aproxima da câmera, garantindo um ar despojado para a situação. O apresentador é visto a partir de dois ângulos, que se revezam: o frontal mostra o mediador em primeiro plano, dando visibilidade à logomarca do Jornal, e o lateral garante maior profundidade ao ambiente e revela o VJ da cintura para cima (plano americano). 
Edgard também explora o super close quando se aproxima tocando com o dedo a tela da câmera como se acionasse o play do VT para "chamar" uma matéria.

A identificação de Rafa com o suposto telespectador do programa é potencializada pelo seu posicionamento corporal. O segundo ambiente garante ainda mais liberdade para a atuação do apresentador, que gesticula e se movimenta pelo cenário de forma inquieta e acelerada: senta, levanta e gira com sua cadeira em diversas direções. Seus enquadramentos são mais variados e podem ir do super close ao plano geral, quando ele é focado de corpo inteiro sobre a mesa. Uma certa inquietude juvenil é também observada no modo de falar do mediador que, diferentemente de Edgard, não costuma usar Telepromper12. É comum o gaguejo e uma sensação de insegurança em suas falas. Mas parece ser mesmo esta a intenção do programa: utilizar um garoto comum, presumivelmente parte da audiência, para conduzir a história de forma a diminuir ainda mais as distâncias entre o texto e o leitor.

Além do aspecto visual, o espaço físico e relacional no qual os mediadores se encontram, o contexto comunicativo caracterizado pela cena de "bate papo" também se sustenta em apelos verbais. O jogo enunciativo é marcado por uma troca de papéis que, em última instância, objetiva potencializar o clima de proximidade com a audiência. São comuns interpelações para um "outro" que se revela cada vez mais próximo: "vamos dar uma olhada?", “aquela música que a gente já conferiu, lembra?”, “... dá para imaginar?”, “vocês lembram dos caras do VMB, certo?”. Também são recorrentes expressões como "se liga aí", "olha aqui”, "vem cá”, "fique esperto", "repare aí". Nessa mesma direção, as gírias identificadas com os grupamentos juvenis são usadas de forma deliberada: "os caras pegam pesado...", “já está rolando na programação...”, "deixa eu dar um toque para a galera...”, "segura a onda ai", "foi só uma sacanagenzinha nossa..." A idéia parece ser mesmo dizer: "fazemos parte do mesmo mundo", "falamos a mesma língua”.

Para se impor como parte de uma "conversa", os VJs se posicionam através do discurso em primeira pessoa, ainda que essa intenção esteja sempre vinculada às marcas identitárias do universo da música pop. Retoricamente, os apresentadores

\footnotetext{
12 Aparelho que possibilita a visualização do texto sobre a câmera, facilitando a leitura do apresentador, que olha diretamente para o público.
} 
dizem "eu" de modo a se colocarem como aqueles que dividem experiências e opiniões com um suposto "tu": "selecionei esse daqui...", "eu escolhi um clipe...”, “eu acho difícil o som do Meat Puppets...”, “deixa eu mostrar para vocês...” etc. Desse modo, os delegados dos discurso do Jornal se fazem confundir com as suas representações pessoais, ainda que não se trate, de fato, um uma simples subjetivação do discurso, mas da inscrição em um universo de hábitos e gostos partilhados.

Esse "eu individual", usado como estratégia retórica, também aparece imbricado ao "eu coletivo" (a MTV e a equipe do programa) e ao "tu" (o telespectador), evidenciando uma subversão dos lugares de fala dos sujeitos da enunciação. A sobreposição das instâncias do campo da realização do discurso (os apresentadores e o programa) torna visível o imbricamento entre a fonte da enunciação e sua figurativização. Isso fica explícito quando ocorre a substituição do pronome eu ( $1^{\mathrm{a}}$ pessoal do singular) pelo nós ( $1^{\mathrm{a}}$ pessoa do plural). Os apresentadores utilizam o nós para se referir ao "eu coletivo": "nós fomos conferir os bastidores...", "a gente bateu um papo com os caras...", "a gente preparou aqui um trecho de uma das apresentações...”, "a gente aqui do jornal...”. Mas o mesmo pronome também é usado para incluir a voz do enunciatário na do enunciador, sugerindo cumplicidade entre os sujeitos, que são colocados no mesmo local enunciativo: “aquela música que a gente já conferiu...”, “estamos ouvindo ai a nossa trilha de hoje...", "vamos escutar um trecho da música inédita...”, "aqui no nosso jornal.”.

\section{O jogo valorativo do Jornal da MTV}

Se o contexto comunicativo provocado pelo programa coloca seus sujeitos discursivos como figuras íntimas, membros de uma situação de partilha, é possível argumentar, em sintonia com Frith (1998), que o "crítico" do Jornal, assim como o "fã" Rafa, mostra-se também como um ouvinte que divide gostos e interesses com uma determinada comunidade de consumidores. A diferença é que, do lugar de fala de jornalista, cabe a Edgard Picolli não apenas expressar suas preferências e desacordos, mas tornar o artista e suas produções explicáveis para o público, levando sempre em consideração para quem ele se dirige. "Os argumentos da cultura pop não 
são simplesmente sobre gostos e desgostos, mas sobre formas de ouvir e sobre formas de ser" (FRITH, 1989, p.8).

Desse modo, o tom pedagógico, quando assumido pelo programa, está sempre associado ao mundo partilhado pelos enunciadores e enunciatários. No quadro Som de Hoje, do dia 13/05/04, por exemplo, Edgard mostra o primeiro disco de Jorge Ben, o Samba Esquema Novo, para falar dos "primórdios do samba rock": "é um disco que dispensa comentários, mas temos também uma parada didática no nosso programa”, sugerindo uma intenção instrutiva associada a uma espécie de "acordo". No dia 18/11/o4, ele ouve junto com o público a faixa Walking on the Sun da banda californiana Smash Mouth e, ao mostrar o encarte com a foto do grupo, afirma: "aqui os caras, vocês conhecem". Mesmo assim, o VJ pede para aumentar o som e utiliza referências genéricas para situar o telespectador: "Smash Mouth era uma banda de Rock'n Roll com uma tendência ao hard core, mas com várias conexões no ska e na surf music". Mais à frente, Edgard demonstra o seu gosto: "É muito boa essa banda, eu adoro essa banda".

Como ilustra este exemplo, o jogo valorativo proposto se vale da explícita adjetivação via texto verbal: "o som desta banda aqui é tão cascadura quanto o nome" (24/11/04), "uma compilação magnífica deste magnífico organista chamado Jymmy Smith" (25/11/o4) etc. Edgard também utiliza ativamente o seu corpo para opinar. No quadro citado, o Som de Hoje, o apresentador costuma explorar as suas expressões faciais quando aprova ou desaprova um determinado som. Nessa mesma direção, o mediador faz uso dos enquadramentos de câmera mais fechados quando vai emitir uma "opinião", de modo a evocar proximidade e, por sua vez, cumplicidade com o seu interlocutor. Aqui, é fundamental atentar para o fato de que este "gostar" não se refere simplesmente a um investimento subjetivo, mas a uma estratégia retórica que passa por uma adequação à "comunidade de conhecimento" (FRITH, 1998) da qual fazem partes os sujeitos de fala do programa. Portanto, quando os apresentadores sugerem um "eu individual", a referência não é a um processo pessoal, mas a uma aposta retórica de aproximação com uma dada audiência que conhece e divide valores com o programa.

Para Frith, no jornalismo musical, os adjetivos são utilizados por duas razões: para relacionar a música aos seus possíveis usos e para localizá-la 
socialmente. Essas duas situações fundam o jogo valorativo produzido pelo programa. A primeira é utilizada de modo deliberado, por exemplo, no quadro Histeria. O objetivo é fazer a audiência se posicionar junto com os VJs em relação aos diversos usos possíveis para as canções através de enquetes ("Que música poderia ser o hino nacional?" ou “Que música você ofereceria para sua mãe?” ou ainda "Qual é a trilha do seu pic nic?”). Já a intenção de promover uma espécie de localização social para a música pode ser ilustrada pela edição do dia 06/04/04 em que foi veiculada uma matéria sobre Rave Gótica, cujo objetivo era contextualizar o significado deste gênero musical. Após a exibição da reportagem, cada apresentador escolheu um clipe “que o deixava depressivo" (sentimento vinculado à cultura gótica), o que evidencia a sugestão de um certo lugar para esse tipo de som. O exemplo também demonstra as distintas posições assumidas pelos mediadores. Rafa indicou o Karma Police, do grupo Radiohead. Já Edgard, assumindo o papel de representante do jornal, evidenciou uma preocupação social em sua escolha, numa tentativa de contextualizar a temática com a realidade brasileira: “O que me deixa deprimido é a nossa realidade, aquela ali que está diante de nossas portas (...) por isso eu escolhi esse clipe que eu acho que tem a ver com a gente", e apresenta "A Minha Alma", do Rappa, clipe documental sobre a situação das favelas cariocas.

A fala autorizada de Edgard é comprovada em diversas passagens. Na edição do dia 17/11/o4, por exemplo, é exibida uma matéria sobre a coletânea PqP - Pop que pariu produzida por três bandas independentes com versões de rock para canções de Sandy e Junior, Rouge e Latino. Ao final da reportagem, Rafa avisa: "pode ficar tranqüilo que assim que o site e o CD ficarem prontos, a gente dá um toque por aqui", mas logo em seguida Edgard retifica ironicamente a afirmação: "Quanto ao PqP ai que Rafa falou que a gente avisa, a gente avisa para você se precaver, certo? Chega de tortura". Esta cena também oferece pistas sobre as escolhas do Jornal.

Os artistas "eleitos" e, portanto, noticiados pelo programa se comportam como protagonistas dos relatos. Além de único sujeito aparente da fala, uma vez que o Jornal da MTV não utiliza repórter em suas matérias, eles estão inscritos na fachada principal do programa e estampados nos diversos cartazes do "quarto" de Rafa. Essas vozes opinam, dizem o que acham de um determinado disco, escolhem seus produtos favoritos, tecem comentários e entrevistam uns aos outros. A investida 
legitima um certo status (um lugar de fala autorizado) para aqueles que, em tese, seriam apenas as fontes de informação do programa. São recorrentes construções de fatos noticiosos que exploram o que determinado artista acha sobre um lançamento musical ou quais são as suas preferências. Em 14/04/o4, por exemplo, Dinho Ouro Preto, André Matos e Beto Lee opinaram sobre a versão que a T.A.T.U fez para How soon is now dos Smiths. "Teve quem amou, teve quem detestou", anunciou Edgard. $\mathrm{Na}$ edição do dia 16/11/o4, Marcelo Bonfá apresentou "nove lindas baladas". Em 18/11/04, a dupla de rap Salazar e Veiga escolheu as "músicas latinas que fazem a cabeça deles”. Já os Titãs sugeriram “parcerias interessantes” em 25/11/o4.

O Jornal da MTV vem oferecendo cada vez mais visibilidade a artistas e grupos independentes, que atualmente têm espaço fixo no programa no quadro Bandas Novas, veiculado às segundas-feiras e em dropes diários exibidos no primeiro intervalo, o que sugere uma relação mais estreita com o público roqueiro em âmbito nacional. Os artistas e bandas agendados, no entanto, são aqueles que também alimentam o fluxo televisivo do canal ${ }^{13}$. A diferença é que, posicionado como um programa de cunho jornalístico, ele constrói quadros narrativos (enquadramentos) para as suas pautas, podendo dar visibilidade ou silenciar alguns nomes. Aqui, o processo de diferenciação, identificado por Frith como estratégia por excelência da mediação dos produtos musicais, é decisivo.

Os artistas que se revezam como notícia são os considerados, pelo programa, “originais”. Essas escolhas refletem o que o autor identifica como o mais comum argumento crítico sobre produção musical. Frith destaca duas posições familiares: 1. a música é julgada no contexto ou através da referência à critica da produção em massa ("música boa" seria original em oposição à música estandardizada) e 2. "música ruim" é relacionada à idéia de cópia, o que reflete novamente um contraste com o que seria "puro". O Jornal da MTV raramente explicita os seus "desacordos", sua estratégia é silenciar. Nomes como Sandy e Junior, Wanessa Camargo, Kelly Kee e KLB, supostamente identificados com um estilo comercial também relacionado ao

\footnotetext{
13 A MTV se insere na engrenagem da indústria fonográfica. A maior parte da sua programação televisiva é alimentada pelos produtos das grandes gravadoras, por isso é raro um desacordo explícito com determinado artista que faça parte deste mainstream.
} 
rótulo "pop" 14 , raramente aparecem no programa. O critério de noticiabilidade aqui se ancora em um tipo de enquadramento; esses nomes só se tornam notícia a partir de um enfoque que borre o engajamento com a dita "fórmula vendável". Júnior, o parceiro de Sandy, aparece na edição de 22/11/04 como o "baterista e vocalista Júnior Lima”. Ao anunciar a matéria, Edgard "se explica”: “o mesmo Junior, aquele da dupla, só que ele está longe da Sandy. Ele assumiu, na verdade, as baquetas e o microfone de um projeto chamado Soul Funk". Justin Timberlake, ex-integrante do grupo NSync, também foi notícia nos dias 15/11/04 e 25/11/04, mas porque dividiu o palco com os Rolling Stones.

A necessidade de diferenciação se ampara também em referências de gênero, identificado como um conjunto de marcas reconhecidas socialmente nas quais se funda um determinado produto. O gênero funciona como uma estratégia de interação, como um modo de situar o ouvinte em relação a uma mercadoria e ao modo de consumi-la, descrevendo não apenas quem são os consumidores potenciais, mas o que os produtos significam para eles (Janotti Jr, 2003). No Jornal da MTV, as marcas genéricas funcionam como porta de entrada para a mediação; as notícias ou comentários sobre os produtos e eventos musicais passam sempre por esta referência: "banda de Oxford com influências do punk music produzida numa linguagem da geração mais nova do britpop" (citação de Edgard sobre o Super Grass, em 17/11/04). A vinheta do quadro Bandas Novas traz uma espécie de radiografia do grupo noticiado, cujo objetivo é localizá-lo e enquadrar o tipo de som para situar a audiência: "Quem: headphone, Onde: São Paulo, Quando: 20o2, Som: 'britpop brasileiro'” (22/11/04).

Tal processo é também ancorado em um hábito comparativo em que as novas bandas são caracterizadas via diferenciação com outras já consagradas. Isso revela que, na mediação musical, identificar através dos gêneros implica em comparações, o que supõe conhecimento histórico e genealógico (JANOTTI Jr, 2004). As notícias sobre os discos e seus intérpretes objetivam organizar o próprio processo de audição: "Qualquer semelhança com o Mellon Collie and the Infinite Sadness na capa não é mera coincidência” (citação de Edgard em 16/11/o4 sobre o

\footnotetext{
14 No ambiente midiático, muitas vezes o termo "pop" é associado a uma certa qualidade ou comprometimento da canção com a demanda de mercado, como adjetivo para qualificar, em tom depreciativo, certos produtos, sempre relacionados à idéia de "formula vendável".
} 
CD da dupla Réu e Condenado), "Quem é fã de Kid Abelha fica de orelha em pé para sacar o som deles" (chamada da matéria sobre a banda nova Brava em 23/11/04).

\section{Considerações finais}

A intenção deste artigo foi compreender o contexto comunicativo criado pelo Jornal da MTV para ambientar a veiculação dos "acontecimentos musicais". O percurso desenhado até aqui aponta para a necessidade de aprofundar as pistas esboçadas sobre as estratégias de mediação (televisiva) da música popular massiva que, como foi visto, pressupõem um interessante jogo ético valorativo. A observação analítica centrada na situação comunicativa construída para e pelos apresentadores do programa ilustrou a importância da discussão sobre os termos valorativos que sustentam essa modalidade específica do discurso jornalístico, o chamado "jornalismo musical" ou, no caso em debate, o "(tele) jornalismo musical”.

\section{Referências:}

CHARAUDEAU, Patrick. "Para uma nova análise do discurso". In: CARNEIRO, Agostinho Dias (org.). O Discurso da Mídia. Rio de Janeiro: Oficina do Autor,1996.

ECO, Umberto. O Conceito de texto. São Paulo: Edusp, 1984.

ELLSWORTH, Elizabeth. Modos de Endereçamento: uma coisa de cinema; uma coisa de educação também. In: SILVA, Tomaz Tadeu da (Org.). Nunca fomos humanos - nos rastros do sujeito. Belo Horizonte, Autêntica: 2001

FABRI, Paolo. El Giro Semiótico. Barcelona: Gedisa editorial, 1999.

FECHINE, Yvana. Estratégias de personalização dos apresentadores do SPTV: uma aproximação semiótica do problema. CD Compôs (GT Mídia e Produção de sentido), 2000.

FRITH, Simon. Performing Rites: on the value of popular music. Cambridge / Massachusset: Havard University Press, 1998. 
GOMES, Itania Maria Mota [et. al.]. Quem o Jornal do SBT pensa que somos? Modos de endereçamento no telejornalismo show. Trabalho apresentado no I Seminário Internacional de Estudos Midiáticos Bahia-Quebec, Programa de Pós-Graduação em Comunicação e Cultura Contemporâneas, Salvador, Outubro/ 2003.

GOMES, Itania Maria Mota. A noção de gênero televisivo como estratégia de interação: o diálogo entre os cultural studies e os estudos da linguagem. In: Revista Fronteiras, São Leopoldo. Programa de Pós Graduação em Comunicação da UNISINOS, dez./2002.

GOODWIN, Andrew. Dancing in the distraction factory: music television and popular culture. University of Minessota Press, 1992.

JANOTTI Jr, Jéder. Aumenta que isso é Rock and Roll - mídia, gênero musical e identidade. Rio de Janeiro: E-Papers, 2003.

JANOTTI Jr, Jéder. Á procura da batida perfeita: a importância do gênero musical para a análise da música popular massiva. In: Eco-Pós, Rio de Janeiro: UFRJ, v.6, n. 2, 2003.

VERON, Eliseo. La semiosis sociale. Barcelona: Editorial Gedisa, 1998.

VERON, Eliseo. Il est là, je lê vois, il me parle. In: Revue Communications, $\mathrm{n}^{0} 38$, Paris, Le Seuil, 1983. 